\title{
Metaphysics of the Self, the Selfie as a Splinter of Modern Culture
}

\author{
Mirosław Pawliszyn \\ Faculty of Theology, University of Warmia and Mazury, Olsztyn, Poland
}

Email address:

mipawl@interia.pl

\section{To cite this article:}

Mirosław Pawliszyn. Metaphysics of the Self, the Selfie as a Splinter of Modern Culture. International Journal of Philosophy. Vol. 7, No. 2, 2019, pp. 72-81. doi: 10.11648/j.ijp.20190702.15

Received: April 13, 2019; Accepted: May 29, 2019; Published: June 19, 2019

\begin{abstract}
Leszek Kołakowski once wrote such a sentence: "Metaphysics pushed out the door returns through the window". These words of the Polish philosopher are still valid. Metaphysics did not die, although it went through intricate paths of criticism. It cannot be practised any more as Aristotle, Thomas Aquinas or Hegel did. Martin Heidegger, Emmanuel Levinas and Maurice Merleau-Ponty introduced it to new paths. One thought seems obvious: metaphysics cannot be practised outside cultural, sociological and psychological contexts. In this paper, we seek metaphysical experience in contemporary culture. It is impossible to mention all the paths followed by culture and metaphysics related to it. Obviously, not every cultural phenomenon "generates metaphysics", but the scale of the changes and redefinitions requires us to seek metaphysics in places where it has not been expected before. One of them is the omnipresent phenomenon of the so-called selfie. A photograph, taken with a smartphone, which documents both the person taking the photo and a trace of the environment they are in, is an attempt to create a new reality. "Creation" and reproduction are complicated cognitive processes. One may ask: is it not an attempt to formulate a "new metaphysics"? Can we provide its definition? Yes, we can. It is the metaphysics of oneself. An important inspiration for the presented reflections is a film by a renowned Polish director, Krzysztof Kieślowski - "Amator". Descartes and Merleau-Ponty cannot be overlooked either. The conclusion I aim to reach is the following: a selfie is a rendering of a person, who is running away from himself and at the same time wants to find himself; who wants to notice, but does not notice; who wants to see, but does not see. This "pursuit" means both an escape from reason, concealed under a hastily conjured smile or seriousness.
\end{abstract}

Keywords: Metaphysics of the Self, Modern Metaphysics, Selfie, Modern Culture, Insert

\section{Introduction}

"You are going to film what you see. You know... this is an idea". Those words are uttered by a friend of Filip Mosz, a worker in the industrial plant near Cracow. A simple man, who perceives the world from his own perspective, which is the communist system, together with related poverty and mediocrity, takes a camera to observe through this device the surrounding world. The eye, armed with this "uninvolved" intermediary, sees his nearest family, his newborn child, the street, people moving along this street, and finally, the factory building, shown only from one side, while the other remains hidden. A "neutral" look on the surrounding reality proves not to be so neutral, as "there is no such possibility". When the outcome of this observation, its "splinter", leads to damage being done to another person, the main character overexposes the film he made. What is the meaning of this act? Desperation, a cry of despair, or a doubt whether the world can be deciphered to reveal its real nature? Together with a recorded film tape rolling along the street, the previous world, created meticulously according to the established rules and unquestionable truths, dies. However, it does not mean that we should abandon seeing, that we can leave our observation point, leave ourselves as the entities who observe the world; there is no such possibility". One solution is available. We should turn the camera and aim it towards ourselves. This does not mean that the scheme involving the observation point and the observed object changes. They both switch their roles. The camera looks at the main character from the perspective of the world, becomes one of those items that "look" at the previous observer. This one becomes an object, though it is different 
from all others. If the world cannot be read without an ideology, in a neutral manner, if looking already becomes speaking, a necessity emerges to start telling about the world. Filip Mosz stops recording the events and starts talking about them, reporting the condition of the world. Is there any convergence between the two narrations, or does one indelibly replace the other? We can only guess, since the director of Amator, Krzysztof Kieślowski, just after starting the next part breaks it off for us to add the rest.

Man is an entity who wants to know the nature of the world, as well as its foundations, substrate and substance. The terms mentioned here are not synonymous; each of them draws our attention to different areas of knowledge. However, all of them can be described with one term: wisdom. Man is searching for wisdom, which means that he wants to know "all things, as far as possible, (...) learn things that are difficult and not easy for man to know, (...) is more exact and more capable of teaching the causes is wiser", and practices "the superior science" which "is more of the nature of Wisdom than the ancillary" [1]. Metaphysics [2] is an attempt to depict the world within the framework established by Aristotle, reaching it through the examination of things, objects, and further on events and circumstances. But is the world grasped equally by everybody, and is the place from which I am observing the world the same as the place occupied by another person? What are the origins of certainty functioning for ages that the view of the object from my perspective is an obvious view, giving me access to knowledge as such? From the moment when René Descartes posed that question, we can legitimately claim that "there is no such possibility" to unquestionably justify this thesis. The French philosopher, just like Filip Mosz, says "you speak about what you see... this is an idea", but this is just an idea, one of many possible ideas, and it is not so obvious. He decides to change the perspective, just like the main character in Kieślowski's film, and look at himself, to start a new story about things and the surrounding reality. It cannot be denied that these are not the same narrations; "there is no such possibility".

A philosophical Cartesian revolt, as well as the moment of turning the camera as shown in the film, marks the beginning of metaphysical self-portrait creation. Filip Mosz sees himself in the dark outline of the lens and it is not important any more who is observing this image from the perspective of a camera operator. Let us emphasize, it can be both anybody and nobody, there can be audience or there can be no audience at all. The only important person is the narrator who tells his story looking at himself. Descartes "looks" into his own consciousness, proving the fact of his own existence, although it is important only for him at the moment when he emphasizes this truth.

We are looking for a metaphysical experience in contemporary culture. It is not possible to list all the tracks it follows. Certainly, not every one of them is "metaphysics generating", but the scale of changes taking place and redefinitions requires us to look for metaphysics in the places where they have not been expected it so far. The two plots, or better, gestures, emphasized above (this Cartesian gesture and the one made by the main character from the film) bring to mind associations with a cultural trace of high importance in present times. Although it is new in its present form, it is certainly the result of processes taking place over years, occurring in the mentality of contemporary man. Even if it proves to be an ephemeron, it will continue to be present for long, perhaps in an altered form. A specific expression of the self-portrait is the so-called selfie and this is what leads us to constructing "metaphysics of the self". The introduction also becomes the conclusion, as the above mentioned gestures seem to herald the end of a certain epoch.

\section{Self-Portrait and Selfie}

A selfie is a variant of a self-portrait. This latter, as the work of art, is just a portrait of the artist creating this work, produced by the artist himself. The practice of self-presenting by artists is not new. We find it as early as in antiquity, although this practice was not often applied then. "The earliest example is surely the Egyptian wall painting from the tomb of Ptah-hotep at Sakara depicting the artist Nianchhptah. But for the text on the wall we would have no idea that this is a self-portrait" [3]. In the Middle Ages, we find self-portraits in sculpture, examples of which include the self-portrait "of Master Matteo in the cathedral of Santiago de Compostela (...) as well as others in Prague and Halle". However, this art developed particularly well in painting, with the examples of images by Rembrandt, van Gogh, Velazquez, Caravaggio and Dali. It is not our aim to discuss these works of art or to analyse the way in which the author depicted himself. One thing seems to be unquestionable - the self-portrait is an image, an attempt to transfer oneself into the work of art, immortalizing one's face. The direction of the artist's activity can be found: the artist is an initiator, the work he creates is an intermediary, a means of expression, but the aim is already beyond those two elements, it is in the one who will look at those works later on. There is no way back in self-portrait. The artist does not want to look at himself; it is other people who seeing the artist are to recognize the epoch, intentions and broadly speaking, the world as such, universe, in which the viewer is stuck. Therefore, we deal here with the speech organ, the incorporated thought of the author, in which he expresses a certain truth about himself.

A selfie, although it is a type of a self-portrait, generally departs from this schema. This is a photo, in which the lens is directed towards the person making the photo. Let us observe, first of all, that contrary to a self-portrait, this is not the means of artistic expression. This is rather a ludic speech, a need for entertainment, a speech that can be used by everybody holding a relevant tool, i.e. a cell phone. "The speaker" does not want to say anything, or inform us about anything, he wants only to look at himself. The author of the first selfie was Robert Cornelius, amateur chemist and photography enthusiast. In October 1839, at the back of the family store in Philadelphia, he made a photo using his own 
camera, sitting motionless for a minute, after which he covered up the lens again. "On the back of the image he wrote "The first light picture ever taken" [4]. However, the true popularity of selfies falls for the modern times and development of social media in the Internet. High quality cameras were crucial in the adoption of smart phones. A selfie is an attempt at depicting reality in a specific way. It is governed by a specific order, in which specific senses and meanings are hidden. Therefore, we are free to pose a question concerning those senses to see the concept of the world hidden behind this unsophisticated art - the expression of contemporary culture. On further pages of this paper, we will balance, many times, between philosophy and art, cognition and technology, and finally, between metaphysics and banality. This is one of characteristic features of our times.

We already said that a selfie is an example of art in which the mutual exchange of viewpoints takes place between the one who takes a photo and the one who is the subject of the photo. We are dealing here with somebody who is observing and who is observed. With such a question, which is apparently not a vain attempt, the associations with the philosophy of Maurice Merleau-Ponty emerge. Let us refer to his thought since it will provide an important context for further analyses.

Seeing something, as Merleau-Ponty claims, is to "become anchored in it [the object - an original note], but this coming to rest of the gaze is merely a modality of its movement" [5]. It means that there is no such situation in which I look at something from a specific, stabilized, fixed, immobilized position. An insight is of a dynamic nature, but in the meaning that this is a movement, a constant activity directed ahead of oneself. This movement was conditioned by the entirety of feeling preceding the one that occurs at present. The entire horizon, the space surrounding me was gathered in it. In the insight "I close up the landscape and open the object". To see the object, it is necessary to calm down, stabilize, withdraw from the surroundings for the object to become light, open to me. This does not mean that the horizon is omitted or discredited. Its components "recede into the periphery and become dormant, while, however, not ceasing to be there". Therefore, everything what makes this horizon, namely, individual objects, each has its own reference, its own background. Perception means entering into a being, emerging and stuck in the universe, and at the same time "to inhabit it, and from this habitation to grasp all things in terms of the aspect which they present to it". A specific object seen by me is also observed from various points, which is occupied by things making up its horizon, and each of them gives me its perception of this object. Looks, perspectives, are multiplied in each gaze, permeate each other, lending themselves their mutual depictions. "The completed object is translucent, being shot through from all sides by an infinite number of present scrutinies which intersect in its depths leaving nothing hidden" [6].

Of course, our perception of the world and individual objects inside this world relies on the judgement of reason, further interpretations and explanations. What is important here is its source depiction, the issue of reaching it in the very moment of its becoming, which should be the moment in which nothing is frozen or immobilized. Therefore, Merleau-Ponty reaches for painting, where he finds such attempts to embrace existing objects. Naturally, it is not our task to provide here a detailed analysis of the entire concept proposed by the French philosopher, but we should point here to elements that are significant for us, such that will allow us to move to further stages of reasoning. What the painter does is not only make an attempt to describe the world, the need to formulate a certain truth about it, but it is "a realization of how a being appears in front of human eyes and what it is as such" [7]. Being is expressed here through the movement of the paintbrush, the play of light, point of view or outline. It can be claimed that being is born in the painter's work and, more precisely, it becomes visible to the one who experiences it. Therefore, there is nothing like a ready-made world which is subject to processing. It is rather a penetrating mutuality, seeing and being seen. Only from this original relation, considered something of secondary nature, are objects given for examination born. The painter in his painting is situated beyond himself; he is rather inside the being, in this original contact, from the inside of which he expresses himself through the canvas. It is no longer "a set of ideas requiring verification, but a description of the event of seeing" [8].

\section{Interjection of Metaphysics}

A question that requires to be asked here is whether the topic undertaken actually has any metaphysical aspects. It cannot be answered with an argument that such a philosopher as Merleau-Ponty makes the painting a path towards depicting metaphysics as the source, and that the painting itself, certainly, is a kind of art, just like a selfie. First of all, it should be noted, without going into detailed differentiations, that metaphysics is "translation of reality in what makes it a reality, recorded by the description of the being" [9]. However, this description is preceded by something that should not be omitted. It is not that we are constantly "metaphysicizing" and each our depiction of the world is a manifestation of this activity. On the contrary, cognition is of superficial nature, it is depiction of objects and phenomena as they are presented, without examining their background, conditions, without looking for final reasons or explanations. Of course, when the bus is late, we pose the question of why it is so, when the keyboard that I am using now does not work I undertake an attempt to repair it, based on the conditions resulting in its defective operation. However, I do not pose a question whether it actually exists, what makes it being like this; likewise, I do not reflect upon the question of whether the bus arriving late or the bus arriving on time is a being that is good or beautiful out of its nature. Metaphysics requires a specific effort to focus, to concentrate on the internal orientation of the person who wants to practice it (leaving aside abilities and relevant 
knowledge). It is also a kind of "art for art's sake", since it is not necessarily as M. Gogacz writes that "our understanding of the reality depends on solving those apparently unrelated questions, and this understanding allows us to master the objects, learn their functions and determine the entire range of practical works realized at this moment, which will bring about this car, this bridge, this health restoring medicine" [10]. This thesis is not obviously false, but it does not mean that we must necessarily accept it. Talking about the specific attitude, we should indicate that this already involves accepting a certain "position" with regard to the surrounding world, situating, locating, and looking at it from a specific standpoint. It is not necessarily the physical management of space to adjust to me (although even this plays here a role), but the mere intellectual depiction of something which is before me, something that I am reflecting upon. I am just as I am, and what I look at, being "here", "somewhere", "somewhat", equipped with some features, and first of all, existing. What is of primary importance? The above mentioned "translation" understood as accepting the "observation" point or "reality", to refer to Gogacz once more? Settlement is nothing more than taking a specific place or position, which determines the type of metaphysics practiced. However, one thing is, as it can be predicted, unquestionable. The observer is always "in his place", involved into various contexts of time and space, while the observed can change as to the content and its scope, or finally, in terms of what it actually is. Therefore, if it can be "everything" that exists, if only it exists, then what happens when the observer himself becomes the observed? Let us emphasize that it is not only about looking into one's own awareness, cognitive acts, will or activities, it is about seeing oneself, and not in the same way as when I observe my reflection in the mirror. In this case, looking at oneself serves a certain purpose, it is also of temporary nature and it is precisely located in the current period of time. The present time, the moment in which I look, is of an "auxiliary" nature with reference to my future - I look to preserve my relevance in subsequent moments in future. Looking at a mirror reflection is not recorded, it is indeed "out of date", although it lasts in this very moment. A selfie is something completely different, it becomes a reality at the moment of taking, a being in which by looking at myself, I observe myself at the same time; by observing, I am observed in it. Let us pose two crucial questions: what do I see when taking a selfie and what do I experience in this activity? Let us add that they constitute a necessary element for creating any metaphysics.

\section{Perception}

It should be observed, in the first place, that the situation in which I look at myself when making a selfie, seems not to differ from the ordinary, everyday perception of the world given to me. The phone and my own reflection shown in it, is indeed one of the objects given to me in the field of view. It is real to the same degree as any other object, of a certain shape and colour, intended for something, with strictly defined possibilities. However, if we take into account the entire sequence of activities accompanying the act of taking a selfie, then the entire event becomes highly specific and original [11]. It is not the case that I have to "learn" what I perceive in the field of my awareness, that I have to assimilate the knowledge of the object I am using. What I am holding in my hand is not unknown to me, it was not extracted from the world as something that inspired me, aroused my interest or anxiety. Metaphysics "launches" at such a moment, inspired by something that was given to me. I can see this, I can analyse and then search for explanatory reasons. With a selfie, something different takes place. The object is known to me, as it has been screened by preceding cognitive acts. Therefore, I am aware of its possibilities, I know what I can do with this object. Thus, the object is not "taken out" of the world, but rather forced into it. The object interferes here with the world, has to do something, according to a plan and purpose. That is not all. This intervention is not performed according to the plan I had arranged in my head, it is not preceded by a purposeful action. The phone does not work in a similar manner as a camera or research apparatus. In the first case, the camera, although it actually interferes with the world, depicts the world to grasp it at a certain moment, immortalize it in a given situation; in the second case, the apparatus grasps a certain fragment of the reality surrounding us to make it more intelligible for the observer. The phone operates on its own, it is not that I grasp something with its use, but it is the phone that records me in the occurring event. The change does not consists in the fact that something different is depicted (the world or me), but in the fact that the phone itself, in its own way, struggles with me, is resistant to my intentions, makes something according to its own plan, possibilities, returning myself to me, giving me to myself as a processed product.

In the situation described above, we deal with focusing attention, specifically directing our awareness towards a given object [12]. However, it is not only about examining and analysing this object. Moreover, it is not about looking for its justifications or explanations in order to search for its foundations or to describe it in the light of the first principle. The look seems not to get inside anything, not to penetrate anything. Therefore, it does not strive for searching for knowledge, it does not want to do something with the object, apart from the fact that it is to be located in a specific position. "Setting" it is of no strictly pragmatic nature, although this claim may seem open to doubt. It happens not only because I want to do something with it or use it for specific purposes, but I rather aim at doing something with myself. Over the entire activity, I am not searching for it, but I am searching for myself, somehow "sliding" over this object. The situation described here is specific and it is difficult to illustrate. The phone is a type of a tool, but not entirely, since I am looking for an appropriate hammer to drive in a nail into the wall, and I am using specific spices to flavour a dish. Here, on the other hand, working towards the aim is exceptional - the tool is at the same time present and absent, used and ignored, to its own way "fragile", in the 
meaning of Jean Paul Sartre. As he writes: "And what is fragility if not a certain probability of non-being for a given being under determined circumstances? A being is fragile if it carries in its being a definite possibility of non-being" [13]. Let us emphasize that in this case it is not about the fact that the phone I use for taking a selfie cannot exist, in the sense that it cannot exist for me. De facto, it is no longer there, not because it has in itself the possibility of non-being, but because I make it absent, somehow putting myself into "its" place. Not seeking to examine the object, to analyse it, to present it in the context, is a significant element of the activity undertaken. Particular pragmatism, using something that is at the same neglected, underlies a new metaphysical project.

Therefore, what do I see or rather what is seen in the case under discussion? A subtle differentiation between those two statements is of crucial importance. It not that I "see something" (myself in the phone? the phone as such?), just as any object placed in the world where the cognitive pattern of the learning subject and the learned object apply, but "something is seen" from double perspective, in which the subject is also the object, something observes and at the same time is observed, something is observed and at the same it observes.

The initial, most obvious answer is the claim that I see a face; I see it, but I am still looking for it. All my efforts are concentrated upon finding the contours, the outline, the trace of what is important in my face. We deal here with bringing out a characteristic feature, with focusing the attention. The entire idea of directing it towards oneself is spontaneous and it is evoked by the background, the context surrounding me. It is this aspect that requires immortalization, retaining, it makes us direct our attention, and consequently, limit the field of view. An inspiration is either an experience of aesthetic nature, in which I state that it is worth being in this place, it has its internal charm, or the willingness to emphasize that it is me and not any other person who is actually in this place. Spontaneity, regardless of what triggers it, is the "awareness of the existence of objects towards which all mental acts, including cognitive acts, are secondary and consequent" [14]. However, any possible similarities with the classical metaphysics project end here. Spontaneity does not lead to transcendental depictions. It remains somehow untouched, closed in itself, and at the same time establishes, in this closure, a specific scheme of depicting the reality. This leads to something that can be referred to as the mutual support, replacement, which occurs between me and my surroundings. I do not pose myself as the viewer, the observer, but I try first to remove the context along with the simultaneous attempt to preserve it. The pushing element is, obviously, myself, and the resisting element is the surroundings in which I find myself. I want here to preserve both myself and the context in which I am placed, while I assign the minimum right of further existence to the latter. It does not necessarily happen by multiplication of the position taken, placing it in the centre, it can occur also in the very intention to be visible as the one, to have everything subordinated to this one aim. It is reflected by the activity of finding oneself in one's own reflection, highly detailed, leaving no doubt that this is me and not someone else. At this moment I am more "outside" than inside myself. We can discuss here the issue of blurring one's own identity, placing oneself outside of one's own person. In this sense, as mentioned above, a classical cognitive scheme is disturbed to such a degree that the viewer somehow escapes from himself, being more in his own reflection than in himself.

Therefore, is the object I perceive my own face, which I want emphasize at any price? And further on, when trying to capture in the same image a certain number of persons gathered next to me, do I rob them of their own identity by using their faces only for the purpose of exposing my own? Finally, does this activity aim at depicting what is given to me in a certain, originally depicted, form? In "metaphysics of the self" constructed here, a completely new cognitive strategy is apparently taking place. It turns out that highlighting the contours and polishing up the shape at the same time gets blurred, dispersed in another activity. The situation gets more serious when faces of other people are next to me. It is hard to imagine a selfie that is not searching for the surroundings at the same time. When we mentioned above the mutual "driving away", the context and the one that is to be the main object of the recorded image, the idea emerged that this first element is to be marginalized, reduced to a minimum. It is not that the background ceases to be important. On the contrary, it is to emphasize my presence, to make it visible, to highlight it. Without it, it becomes pointless to search for the contour, for the face outline, as this activity transforms itself into nothing more than a selfportrait. However, the point is that it gets gathered by me, captured, seized. However, my face does not exist without the elements that place it here. Therefore, it is possible that by emphasizing myself, I blur myself at the same time; by specifying, I disperse. But I cannot say that I am present and absent at the same time, since in the act of grasping the image represents something, I am going to be thoroughly with what is present around me. Capturing the background, stubborn willingness to make it mine, is nothing more than intensification of the activity, an attempt to distance myself and at the same time to establish a permanent link with the landscape. It happens at this moment, here and now. The present time, being captured and recorded, is happening when I am searching for the face and for what surrounds it. The entire effort aims at grasping the time, even subjugate it in the recorded image. It was described, so accurately, although in another context, by Emmanuel Levinas: "Action is this taking up. Action is then by essence subjection and servitude, but also the first manifestation, or the very constitution, of an existent someone that is" [15].

We may pose a question: what is seen in the act of taking a selfie? If the face is blurred, and at the same time it is so much searched for, established as the one and not another, then it is possible that I want to grasp myself as a human being, a person who is located in a precisely described point of space and time. It is not that a selfie should emphasize the 
shape, outline or physiognomy, but myself as a human being, who is allowed to experience the moment. The term "experience" is important here, since in the "metaphysics of the self" project, the cognitive distance is exceeded. I do not only observe something that exposes emotions I am filled with. These are the emotions that are to be recorded, without any inhibitions. We can therefore say that nothing is forbidden at this moment, no behaviour weakens the value of this act, no behaviour makes it deserve a lower level of respect or to be claimed worthless. Metaphysics, at least by a certain time, emphasized the meaning of what is objective and intersubjectively verifiable. In a selfie we receive a project, which is only mine, designed from scratch as my own project, and importantly, it comes into view for its future observer as the actual evidence of some events. The surrounding world is not degraded, considered less worthy only because it is depicted by emotions taking place, or in other words, what I did with this world is not its reduction or depreciation for the observer. My presence makes the world thoroughly reliable, true. What certifies this fact is nothing newer than my (our) being here. We are allowed to assume that the rank is established not by the face itself, but by the human being as such, the person. But am I really here as a person, or rather as an outline of a face forcing its way into the lens, which obscures with a grimace the image of a person? Let us emphasize that what distinguishes the phenomenon described here from a typical photograph depicting me in such a situation, or a self-portrait, is the element of capturing the presence. The photo shows somebody as he or she is; its typical feature is that I am in this photo situated against a certain background, blended in the horizon and surroundings. There is no place for mutual struggle, for pushing out. Moreover, in the photograph I am depicted at a given moment of my life, in entire naturalness or even innocence. What is given to the entity looking at the photo is a fragment of the natural world, filled with me, as well as with everything surrounding me. On the other hand, the self-portrait is searching for my own "self", with everything that is inside me, with the entire truth about me, it is somehow bringing myself out of the world, which is made arduously and with reverence. I want to say with the selfportrait: see who I am, see what the world I live in looks like. A selfie is another way of depicting or expressing reality. This is an attack of the present day occurring now, even an attempt to dominate me. Mutual struggle between me and the surroundings is the dispute taking place inside the time going on. On one hand, I try to grasp the world which I found in a given situation, while on the other, it itself orders me to stop, does not allow me to go on. We can say that the whole essence of a selfie, artificiality underlying it and expressed by a programmed facial expression, emerges from the inside of this dispute. Therefore, it is not the given human being who is revealed in it, but rather as a fragment of me, somebody who is only here and now, without reference to my own identity, experienced history or the desires I feel.

The issue of the background presented in a selfie, surroundings, emerges many times in the descriptions quoted above. Perhaps this is what I see in the foreground? At this moment, a selfie becomes nothing more than an intermediary, something through which I observe the world surrounding me. The problem lies in the fact that my attempts to capture the reality have highly involved nature. There is nothing about the alleged cognitive neutrality, the willingness to tell what the world is like, what objects it is composed of. A captured waterfall is not something that presents natural beauty, in itself, the construction does not express its proportions, the street is not "settled" by those who currently are moving along it. I, or we, are to be the main character, and everything else is to be the background - altered and prefabricated. Of course, the background made us stop in this place and caught our attention. But a selfie has a destructive element which causes the surroundings to lose its expression and internal meaning.

Finally, there is one more issue. The presence of others who are possibly depicted in the image together with me has been mentioned here several times. Perhaps another person is the one whom I really see, who becomes the foreground figure, brought out from the world by me. It is not that I am important or my surroundings are important, but rather somebody who is with me and next to me, just at this very moment. Can we "suspect" somebody who performs this activity of such far-fetched altruism? First of all, we notice that in the case under discussion it can be clearly seen that the world surrounding us actually does not matter. It is only a stimulus, an inspiration, something to be used and nothing more. Further on, we also deal with a specific conflict that occurs between me and the "co-present" persons. This is taking place somehow below the surface, as in the photo presented everybody is reconciled, oriented towards one direction, feeling the same emotions. Yet, a selfie has actually only one central figure. This is me and only me. This is me whom I introduce into the world presented, while others try to join, keep pace with me. But there is always only one main character in the photo, the one who wants to be discerned; others only seek this privilege, always remaining in the starting point, which cannot be changed.

\section{Experience}

The question of what I experience in the entire "action" related to taking a selfie is equally complicated as the previous one. Metaphysics assumes that I experience something concrete, its living presence. It is, first of all, experienced spontaneously, and we are "philosophizing in a primitive and pre-scientific way on this subject. We meet this irresponsible philosophizing, although certainly containing some important truths and deep wisdom, in the broad field of so-called common sense" [16]. The "primary, spontaneous existential court, confirming the real existence of reality, and reassuring us in this reality" is born only based on the natural contact with the world.

Trying to examine the "metaphysics of the self" created, we can clearly see that this natural cognitive order is disturbed. My contact with the world is following two tracks: 
first of all, it is perceived in its certain excerpt, fragment; secondly, I have in my hand a tool useful for realization of this aim. Spontaneity seems to be realized with this first element, something that enchanted, delighted me. However, the analyses conducted so far let us claim that it is also disturbed. Am I actually fascinated by the surroundings, the world of things, circumstances taking place or perhaps something else is triggering my interests? What is important is the fact that I am in this place and this fact should not, in my opinion, be ignored. It could be said that a kind of pressure, constraint exists in the very intention of taking a selfie, which can be formulated in the following way: see (those who look at the image I made), it is me who is here, this is me who marks the place with my own presence. The phone, as we have said, is a necessary tool, which is well known to me and plays an ancillary function for me. Common sense, being the first step in recognizing reality, does not seem to function and does not lead to wisdom as such. It is replaced with a sudden need, an uncontrolled emotion. Consequently, there is no opportunity to make a judgement concerning what actually is, not only in existential terms, since the fact of existence of any excerpt of the world is assumed in an unreflective way, but also in essential terms, confirming that something has such or other properties. Both are replaced with one: see, it is me who is just in this place! However, it does not conceal any deeper content and has an expansive nature both towards the existing world, as well as others who will be future observers of the "work" I produce. A specific uncommonness of the occurring process, its expansiveness, is a significant element of the "metaphysics of the self". Let us emphasize that it has a spot, one-off nature. This means that it is "expressed" at the moment of taking a selfie, but it is so meaningful that its power seems to be hidden in every moment where the taken image will be looked at later on. The content must remain in its present form and seems not to lead to finding any other; in other words, the very moment of taking a photo contains everything that it could have, without the possibility of any further interpretations. The reality of the entire situation also seems to be distorted; the moment experienced with exaggeration, and its circumstances leave an impression that the entirety is prepared by, firstly, upsetting the proportions between myself and the surroundings, and secondly, by artificial imprisonment of time, which has been already referred to in this paper.

What is typical for the issue under discussion is something that should be described as focusing, what can seem, at the first moment, contrary to stressing the emotions accompanying the act of looking at oneself. Everything that precedes this act evokes a specific reaction in me. We have already told that the moment of directing the lens towards oneself is at the same time related to the intention of suspending time. This means that the presence is unnaturally stretched here, which is obviously contrary to what on this issue was written by, e.g. St. Augustine. Let us quote: "If an instant of time be conceived, which cannot be divided into the smallest particles of moments, that alone is it, which may be called the present. Which yet flies with such speed from the future to the past, as not to be lengthened out with the least stay. For if it be, it is divided into past and future. The present hath no space" [17]. We have to separate two perspectives: the one who takes a selfie and the one who observes the activity. The first one, by focusing the attention, seems to accumulate both its past and future, to suspend the passage of moments, to focus the entire reality around himself, to somehow force it to abandon the passage of time into which it is forced and to respond only to the one who performs the activity. This focusing and seizing the world are other, as it seems, typical elements of the "metaphysics of the self". The present day, contrary to the quoted fragment of Confessions, stretched and experienced "from the inside", seems to have no end. The other one, i.e. the one observing the entire action, has an impression of being neglected in the scene; there is no place for him in the world created in front of his very eyes. The present day, together with time, does not seem to pass for him or "fly to past".

In this quite unnatural situation, the subject, i.e. the performer of the action is in a specific position. And although this problem has been mentioned above, it still requires additional remarks. Spontaneity, along with focusing, which are difficult to distinguish, bring about the impossibility of taking a position that would be proper for the subject. If its status is unclear, then the recognized object is underspecified. Let us emphasize that if the "metaphysics of the self" is nothing else but the quintessence of contemporary culture, then it cannot escape from its influence. One of them is the issue discussed here. As Michel Foucault, struggling with the issue of "self" and its references to the surrounding structures, wrote: "the subject who knows, the objects to be known and the modalities of knowledge must be regarded as so many effects of these fundamental implications of powerknowledge and their historical transformations. In short, it is not the activity of the subject of knowledge that produces a corpus of knowledge, useful or resistant to power, but powerknowledge, the processes and struggles that traverse it and of which it is made up, that determines the forms and possible domains of knowledge" [18]. If we want to adapt this fragment for our needs, it should be phrased as follows: "the subject who knows, the objects to be known and the modalities of knowledge must be regarded as so many effects of these fundamental implications of events occurring in the world, acting upon as and at the same time evoked by us, both in history and today. In short, it is not the activity of the subject of knowledge that produces an image in the form of a selfie, but the mere modalities of the surroundings, time as well as the unnaturalness of the situation taking place here and now that traverse the "self" that determines the forms and possible domains of knowledge". The conditions made the subject not fully autonomous, not entirely aware of the event taking place and the world towards which he wants to assume a certain attitude. He is in the situation in which he seems to search for himself, locate himself, even though this effort is doomed to failure from the very beginning. What is characteristic is the fact that in the activity performed, in the 
undertaken attempt to grasp a fragment of reality, he sees himself as the one who is trying to take a specific place in the world and, at the same time, while looking, he does not know the point from which he is looking. The awareness of holding this position is indeed important in the entire process of learning and acquiring any kind of knowledge about the world. It is either multiplied or minimized on various levels, but it is always permanent. This impossibility becomes particularly troublesome here. It would be difficult not to mention one of important features describing "metaphysics of the self": I am present at the point where I am standing, I am looking at the screen directed at my face, and at the same time I am in the place where I see just myself. I claim that the situation does not occur with the same intensity, if it occurs at all, when I look at my reflection in the mirror or create a selfportrait. In a selfie, I make an effort and I focus on it in order to resemble myself to a maximum degree. Those two places that have been distinguished are trying to become one. One wants to be transformed into the other, to level any differences, and at the same time I, being in both of them, know that the distance is insurmountable. Therefore, a question should be posed: where am I actually? - here, where I stay and look, or over there - where I see my own image? Neither of those places seems to be privileged. On the basis of "metaphysics of the self", I anxiously ask the question whether I am at all, striving at the same time to emphasize my own presence in the place in which I am currently staying. Genuine dramatic nature of the circumstances is apparently absent in the prevailing casualness accompanying creation of a selfie, but looking deeper into the issue, it is hard not to notice it, for instance, by following the ambiguity accompanying this activity.

Let us explore another issue. The very touch, the moment of taking a selfie and synchronizing this moment with seeing things that one wants to capture, is of significant importance for the process. It should be strongly emphasized that this is not about the mere technique of performing acts leading to taking a picture. Spontaneity of the action, already mentioned several times above, related to focusing, is crowned in seeking for precision in the way of experiencing the world as such. This is what makes the entire complexity and significance of the phenomenon under discussion. In the first place, we have to emphasize the role of a touch. This sense becomes an important element leading to achieving the objective. However, it is not a touch in its pure form; it includes a certain internal disruption, a defect. Let us analyse this fragment in more detail.

It is unquestionable that "metaphysics of the self" finds a culmination point at the moment in which a proper button is pressed on the object recording an image. The entire complexity of processes previously occurring, as mentioned above, finds its fulfilment and reason. This gesture becomes a necessary condition to record the state of things happening around, which I am observing. Touching plays a crucial function, just like turning an ignition key in the car, which makes driving possible, or starting a device, which permits us to conduct an experiment in the laboratory. In each of those cases we deal with a gesture which has its own hidden meaning and it is based on nothing more than touching the one and not the other point. On the basis of metaphysics, it is difficult to specify one moment, one gesture in which it is set in its internal movement. This can be, for example, bewilderment with being, the pure fact of its existence, fascination with the beauty of the world or realizing its power, experience of its ethical or mystical character, and finally discovery of "self" as a foundation of existence. Nothing refers here to touching something in a physical sense, but it should be emphasized that if we treat a touch more broadly, then it can mean the very moment of spiritual or intellectual "contact" with what moved the learning subject. The category of touch becomes therefore highly significant and it should be referred to now and adjusted to the discussed problem. First of all, we observe that this notion is today of secondary importance, it is neglected and marginalized. We rather "take", "grasp", "get", or "finger", "examine" and finally "push" or "grab" something. As regards the subject of our interest, it also seems that we rather take a photo than touch the point which makes it possible to perform the activity.

The very notion is in its meaning subtle, marked with shades and nuances. It is certainly a departure towards something; therefore it is related to overcoming the selfishness, transgressing oneself. It has its own direction, which is strictly specified, it also has an intention, an objective, which lies in the touching subject. The touch assures me that something exists, that it is in the field of my presence, but also that I am not alone, that this something surrounds me and supports me in my being. Therefore, it does not so much establish, as strengthen, in existence and makes it richer and fuller. The road leading to discovery of this truth is something that constitutes the entire subtlety of the phenomenon under discussion. In the first place, "a touch allows us to experience the materiality of the object, upon which, its entire usefulness as a tool will be built" [19]. The materiality of the object is an opportunity to draw attention to it, to become interested in it, to bring it out "towards" me. A touched object leaves an impression on me, marks me with itself, which can lead to a thought related to responsibility for what is touched. Following this line of thinking, we can say that it includes the moment of innocence, a specific immaculacy of the touched object. The materiality of what is touched is its own internal structure and its usefulness is something that it is able to do on its own, to realize, without prejudice, without detriment to its own structure. Therefore, it is not a gesture in which I can (I am able to) do something with the object, but emphasizing, appreciating the meaningless of being as such. One more thing should be noted. A touch has a spot-like nature, it happens here and now, at the moment in which it fulfils itself. When touching, I do not want to do anything more, I do not plan anything and do not assume that it is "for something" or "for any purpose" and if it is so, then we talk rather about use or grasping something.

The moment in which I am taking a selfie, creates a 
"metaphysics of the self", is linked to a touch, but at the same time, it involves its denial. After all, I am not grasping an object which is necessary at this moment, and I am not using it, either. This latter statement can seem problematic, since it may seem that this is just what is taking place: I am using this object to perform a specific activity with its use. It is not so obvious, this is not a situation similar to the one when getting on a bus, I am grasping the handrail or when I am taking hold of a hammer if I want to hammer a nail. The used object is unnoticed, even marginalized, to some degree [20].

With regard to the above mentioned idea of specific focusing while taking a selfie, this notion at this point, I presume, becomes clearer. Its multiplication is related not to using the phone, but actually to touching it, and in such a manner so that the entire reaction between myself (us) and the surroundings is recorded in a proper way. The touch "wants" here to be precise, even solemn, but the problem lies in the fact that it disperses at a certain moment and its primary meaning becomes blurry. Therefore, the touch aims towards the concretum, it is realized here and now, is extracted for the common being, "determines a certain type of cognitive efficiency, in which - focused and concentrated - I can spontaneously work" [21], for instance, by establishing a kind of interpersonal link. Meanwhile, paradoxically, at the moment of taking a selfie, the mere touching becomes insignificant, and is replaced with the mutual struggle with the surroundings, searching for the facial contours and with spontaneity of escaping meanings. The touch is, to some extent, deceived by the stubborn willingness to find oneself, and the object, which was necessary a moment ago, becomes only a means of use. There is no question about holding the object in the hand, it is rather a grip with no traces of solicitude or care. This abandonment of something that used to be required, absolutely necessary, is another trace of the "metaphysics of the self". It becomes not so much the way of talking about the subject or establishing it according to the intended guidelines, as an act of abandoning the object, a peculiarly understood betrayal.

\section{Conclusion}

Let us summarize. The issue that we tried to explore is a significant part of contemporary culture. It can be even argued that this part actually is at its core. The willingness of defining himself in the world, in given situations and circumstances has been an irresistible tendency of human beings for ages. Therefore, I do not exist without the world, and the world does not exist without me. However, man is still the one who tries to be in its centre. It is expressed by continuous emphasis placed on his own role, the willingness to dominate at the intellectual, mental or physical level. Consequently, he is in a permanent dispute with the surroundings, trying to take back as much place as possible from the world, and allot it for himself. Let us observe that in everyday life practice, in creating knowledge, it is the world that is to be learnt, it is to be adjusted to our, human, dimension. A selfie, which has been discussed in this paper, is a telling example of the dispute taking place, and the screen of the device is one more battlefield.

It shows my face, and somehow additionally, also my surroundings and people who try to join the action taking place. The aim of the viewer is to emphasize the entire sequence of experiences related to the place of his present stay, in one, recorded moment. This is not a simple photograph, as it reveals the specificity of the cultural dispute taking place in our times. It shows a specific approach towards the world which opens before me, towards the subject held by me in my hand while taking a selfie. Consequently, it can be claimed to be one more variant of the subject-object relationship, in which the established boundaries are blurred, in which the elements not so much swap their places, as they both become the former and the latter. The question that opens before us is as follows: what is revealed inside this perspective of blurring places and muddied meanings?

The text refers to "metaphysics of the self" which, as it should be added, is not a direct successor of Descartes's achievements. Reality is not demoted here, and its existence is not called into question. On the contrary, the world surrounding me does actually exist. Moreover, it deserves our attention, yet not to be learnt in the light of the first reasons but to extract and show oneself against its background. The means leading to a goal is a specific device, necessary on one hand, and on the other treated as absent, paradoxically redundant. Metaphysics discussed here is based on a single and spontaneous experience, which eliminates cognitive distance, the ability make a judgement and evaluation. These experienced emotional states are recorded and tell everything about the event taking place; just initiated, they become the fullness of expression. This one-off nature includes something that can be referred to as the heart of the matter. As it is not captured from a distance, it is not possible to depict it as something that is given, something that I try to reach through inspection or intuition. It has an imposing nature, it is as it is, and it does not allow me, as the viewer, to verify it or to question it. The expansiveness is an inherent element of "metaphysics of the self", it absorbs the one who is involved into it. Me, as the subject, saying openly: the one who is taking a selfie, I am fighting a losing battle while wanting to preserve my autonomy. It is not that I am annihilated and my status as the subject is taken from me. I rather become a subject-object, somebody who is and who is not, somebody who fights for his place in reality, and at the same time knows that without this reality the entire project becomes pointless; without me, but also without the world around me, there is no selfie; without a selfie there is no me. Without it, I lose the guarantee of being precisely in this place. The feverishness of this situation is manifested through excessive emotions, facial expressions or a pose. A playful element displaces reason and becomes a key to practicing the "metaphysics of the self" 


\section{Supplement}

"You are going to film what you see. You know... this is an idea". The intention of the main character in the film by Krzysztof Kieślowski is an attempt to capture the world as it is. He goes further on. From a certain moment, a camera reaches deeper and starts to "see" not only events, but also rules, principles which are hidden somewhere and that are still to be found. They have explanatory power. Explanation is indication of reasons, clarifying why it is like this way and not the other. Amator clearly shows that the belief that they lead to results that are always the same and straightforward is an illusion. They are left to be subject to human interpretations, distortions, mistakes and expected benefits. Of course, the aim of science (a scientific approach to metaphysics) is to limit such impacts to the maximum degree. Is this task feasible? Looking at the history of thoughts and inseparable human attitudes, we become more and more sceptical. What should we do? We should direct the look at ourselves, just like Filip Mosz. What do we see? Our own face. How can we interpret it? Only as it appears.

A selfie, with its entire banality hidden inside, tells us something about us and the world, leading to deeper, more fundamental truths. We are given a man who seems to be running away from himself, and at the same time a man who is searching for himself, who wants to perceive and does not perceive. This pursuit means at the same time escaping from reason, hidden under the hastily produced smile or solemnity, put on "in the right time". We are given somebody who is trapped in his own gaze, ceasing to see at the same moment. We perceive somebody who struggles with the world, pushing it away from the lens, looking for the place for himself, necessarily in the foreground. Taking a selfie, using a tool, I look for a moment inside myself, and I utter the familiar sentence: "I see, therefore I am". I am only now". I confirm myself in an empty look. It is not a catastrophic vision; this is nothing else but the "metaphysics of the self".

\section{References}

[1] Aristotle, Metaphysics I, 2, 10-15, translated by W. D. Ross, eBooks@Adelaide, 2015.

[2] Using this term, I will refer to the so-called classical, Aristotelian-Thomistic metaphysics, which will provide the framework for the "metaphysics of the self" which is related, or more precisely, included in the act of making a selfie and a product of this activity.

[3] C. Brush, From the perspective of the self. Montaigne's SelfPortrait, Fordham University Press, New York 1994, p. 18.

[4] https://publicdomainreview.org/collections/robert-corneliusself-portrait-the-first-ever-selfie-1839/
[5] Maurice Merleau-Ponty, Phenomenology of Perception, translated by Colin Smith, Routledge and Kegan Paul, London and New York, 2003, p.78.

[6] Maurice Merleau-Ponty, Phenomenology of Perception, translated by Colin Smith, Routledge and Kegan Paul, London and New York, 2003, p.79.

[7] P. Dybel, Malowanie ciatem czyli filozofia malarstwa Merleau-Ponty'ego, ASP w Gdańsku, Gdańsk 2012, p. 4.

[8] J Migasiński, Metafizyka i malarstwo, In: Sztuka i filozofia 7 (1993), p. 62.

[9] M. Gogacz, Ważniejsze zagadnienia metafizyki, In: http://www.katedra.uksw.edu.pl/gogacz/ksiazki/wazniejsze_za gadnienia_metafizyki.pdf, p. 6 .

[10] M. Gogacz, Ważniejsze zagadnienia metafizyki, In: http://www.katedra.uksw.edu.pl/gogacz/ksiazki/wazniejsze_za gadnienia_metafizyki.pdf, p. 22.

[11] I am comparing the moment of looking at oneself while taking a selfie and looking at the world. The former and the latter are similar, in both cases there is me and something that is currently given to me.

[12] The same happens when starting with a spontaneous contact with the object, I proceed to the attempt to explain its causes.

[13] J. P. Sartre, Basic Writings, edited by Stephen Priest, Routledge, London and New York 2001, p. 143.

[14] M. A. Krapiec, Metafizyka, Redakcja Wydawnictw Katolickiego Uniwersytetu Lubelskiego, Lublin 1985, p. 33.

[15] E. Levinas, Existence and Existents, translated by Alphonso Lingis, Kluwer Academic Publishers, Dordrecht / Boston / London, 1978 p. 18.

[16] S. Świeżawski., Byt. Zagadnienia metafizyki tomistycznej, Wydawnictwo Znak, Kraków 1999, p. 119.

[17] The Confessions of Saint Augustine, Book XI, 15, translated by E. B. Pusey, retrieved from https://www.gutenberg.org/files/3296/3296-h/3296-h.htm on 24.01.2019

[18] M. Foucault, Nadzorować i karać, przeł. T. Komendant, Wydawnictwo Aletheia, Warszawa 1993, p. 29.

[19] T. Sławek, Cienie i rzeczy. Rozważania o dotyku, [In]: W przestrzeni dotyku, ed. B. Konopka, MDK Batory, Chorzów 2009, pp. 16-17.

[20] The Author wants to emphasize that this phrasing is a mental shortcut, since here we should not omit the insightful analyses of Martin Heidegger ("handiness of the object") or Ludwig Wittgenstein ("means of use").

[21] T. Sławek, Cienie i rzeczy. Rozważania o dotyku, [In]: W przestrzeni dotyku, ed. B. Konopka, MDK Batory, Chorzów 2009, p. 27. 